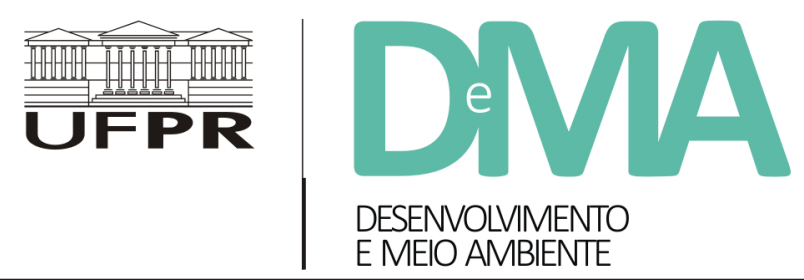

\title{
Políticas de adaptação à luz do mundo-da-vida: perspectiva fenomenológica das mudanças ambientais
}

\section{Adaptation Policies in the Light of the Lifeworld: Phenomenological Perspective on Environmental Changes}

\author{
Rafael Bastos FERREIRA ${ }^{1 *}$, Eduardo MARANDOLA JUNIOR ${ }^{2}$ \\ ${ }^{1}$ Programa de Pós-graduação em Desenvolvimento Sustentável do Trópico Úmido, Universidade Federal do Pará (UFPA), Belém, PA, Brasil. \\ ${ }^{2}$ Faculdade de Ciências Aplicadas (FCA), Universidade Estadual de Campinas (Unicamp), Campinas, SP, Brasil. \\ "E-mail de contato: rafaelbastos@ufpa.br
}

Artigo recebido em 4 de maio de 2017, versão final aceita em 28 de setembro de 2017.

RESUMO: As políticas de adaptação são uma urgência de nosso tempo. No âmbito das mudanças drásticas do clima, suas diretrizes essenciais têm visado à criação de medidas, estratégias e iniciativas, com o objetivo de adaptar a realidade humana ao aumento das condições de risco, perigo e vulnerabilidade. Com o objetivo de contribuir com a temática, recorremos ao conceito de mundo-da-vida (Lebenswelt) por meio da problematização de três temas fundamentais: conhecimento, cultura e ética. Pretendemos demonstrar que as políticas de adaptação podem encontrar conhecimento suficiente no solo do mundo-da-vida, do qual se podem vislumbrar, formulações de políticas públicas mais humanistas, isto é, para além das limitações de cunho objetivista, dicotômico e hierárquico.

Palavras-chave: mudanças climáticas; fenomenologia; vulnerabilidade; política pública.

ABSTRACT: Adaptation policies are an urgency of our time. In the context of drastic climate changes, their essential guidelines are aimed at creating strategies, measures and initiatives in order to adjust human reality to the increase of risk, hazard, and vulnerability conditions. In order to contribute to the theme, we propose the discussion of the concept of lifeworld (Lebenswelt) through the problematization of three vital issues: knowledge, culture, and ethics. We intend to demonstrate that adaptation policies can find sufficient knowledge in the soil of the lifeworld, which can to glimpse, formulations of public policies more humanistic, that is, beyond the limitations objectivist, dichotomous and hierarchical.

Keywords: climate change; phenomenology; vulnerability; public policy. 


\section{Introdução}

As políticas de adaptação, como medidas e estratégias em resposta às mudanças climáticas, têm se tornado uma importante ação de enfretamento da urgência das questões ambientais. No entanto, estas têm se mostrado pensadas, especialmente no caso das recentes políticas que envolvem a construção de uma governança das mudanças climáticas globais, com base na escala internacional, operando o processo de top-down para a definição de políticas nacionais, regionais e locais (Marandola Jr., 2013).

Este e outros debates concernentes aos problemas ambientais levantam questões para além dos problemas específicos, trazendo dilemas que se referem à possibilidade da existência humana na Terra. Em outras palavras, assuntos relativos à ética, à razão e à cultura têm sido permanentes nessas discussões. No entanto, as políticas governamentais pouco exploram esses valores, prevalecendo muitas vezes análises pragmáticas pautadas em uma racionalidade tecnológica e econômica, distante do cotidiano das pessoas (Noguera, 2004).

Nesse contexto, as políticas públicas - ou políticas de governo -, como aponta Cavalcanti (1997), devem levar em conta uma compreensão dos limites e das características ambientais (resiliência) e um modelo de desenvolvimento que implique a sustentabilidade social, ambos fundados em uma renovação da própria racionalidade que orienta não apenas as políticas, mas a própria construção dos conceitos de desenvolvimento e sustentabilidade (Leff, 2001). Isso implica outra epistemologia, ou seja, a busca por outro marco conceitual que nos permita ressignificar as relações sociedade-ambiente. Floriani (2013) sugere a emergência de uma epistemologia da diversidade, pautada não apenas na compreensão da diversidade ecológica e social, mas também na diferença inerente aos diferentes saberes e formas de conhecimento. Segundo o autor, é necessário pensar o desenvolvimento em uma chave interdisciplinar, o que permite superar as limitações de uma visão excessivamente atrelada à economia e à ecologia, marcos deste debate até os anos 1990.

Floriani (2013) destaca o sentido multicêntrico do termo "meio ambiente", retirando-o do campo estritamente semântico-conceitual acadêmico e dotando-o também de importantes aspectos culturais, os quais envolvem visões de mundo, representações e imaginações que estão ligadas não apenas a perspectivas disciplinares das ciências, mas também a vivências e valores culturais territorialmente significados. É preciso, segundo Leff (2001), combater o racionalismo presente no debate ambiental (herdeiro da ciência moderna), buscando-se, assim, uma epistemologia ambiental fundada em um diálogo de saberes e, como defende Noguera (2004), no reencantamento do mundo.

Desse ponto de vista, são necessárias estratégias para incorporar às discussões a constituição das políticas de adaptação em outros saberes, significados e experiências vividas socialmente. Este artigo se apresenta como uma contribuição para essa epistemologia da diversidade, nos termos de Floriani (2013), trazendo a perspectiva fenomenológica do mundo-da-vida (Lebenswelt) husserliano como fundamento vital para as políticas de adaptação (Ferreira, 2016a).

O conceito de mundo-da-vida, presente com mais força na obra tardia do filósofo Edmundo Husserl (2012a), não se refere a um receptáculo, ou mesmo a uma escala local, conforme a interpretação de um mundo cientificizado. O conceito de mundo-da-vida se mostra como um horizonte complexo, 
que visa à compreensão de redes e relações forjadas na intersubjetividade (Ferreira, 2015). Husserl (2012a, p. 133, grifo no original) chama atenção: "No viver em relação mútua, porém, cada um pode tomar parte na vida do outro. Assim, o mundo não é de todo modo existente somente para o homem isolado, mas para a comunidade humana [...]". Para compreender melhor, então, o significado do mundo-da-vida devemos nos referir em dimensões vividas, culturas particulares e concretude histórica: expressando experiências, relações comunitárias em que os indivíduos constroem formas de (sobre)vivências, identidades e valores mutuamente constituídos.

Segundo Korelc (2013, p. 346), a “[ [... estrutura do mundo da vida, em relação ao qual em última instância a subjetividade pode ser compreendida, é uma estrutura de metas". Desse modo, o mundo-da-vida é o mundo da doxa, e nada nele pode ser desvalorizado. Diante disso, entendemos que esses conhecimentos devem ressoar, com urgência, nas tomadas de decisões políticas no contexto das mudanças ambientais em diferentes escalas. Trata-se de, para além da racionalidade presente na construção das políticas, pensá-las no solo do mundo-da-vida, o que nos remete a: a) retornar às experiências cotidianas e, por outro lado, b) ampliar os valores que limitam as políticas de adaptação dentro de uma lógica econômica e tecnológica: incluindo a ética, cultura e o conhecimento. Com isso, o retorno ao mundo-da-vida como fundamento vital vai expor, primeiramente, uma crítica à racionalidade política para, em seguida, fundar-se nas experiências das próprias pessoas em sua vida cotidiana.

Tendo em vista que a adaptação é uma condição necessária de nosso tempo, a qual visa à possibilidade de pensar estratégias e inciativas diante das mudanças climáticas, tais valores preenchem as lacunas (tal como: a importância da subjetividade e intersubjetividade, o conhecimento advindo da experiência cotidiana, o reexame epistemológico) das quais a reflexão sobre o mundo-da-vida buscará ampliar o conhecimento sobre o assunto e seus debates correlatos. Com efeito, este artigo visa descortinar conhecimentos e valores que possibilitem ampliar as medidas e políticas de adaptação.

Este caminho aponta uma nova atitude de responsabilidade - para além de uma racionalidade que emprega visões causais e hierárquicas -, pautada em uma perspectiva ética do conhecimento e da possibilidade da renovação do conhecimento e da própria política.

\section{Problematizando o conceito de adaptação}

As políticas de adaptação surgiram no início deste século como uma resposta às mudanças climáticas, ora sendo pensadas em nível local e visando pequenos ajustes, ora sendo pensadas sob as compreensões que objetivam metas com prazos mais longos (mudanças estruturais ou de paradigmas). Essa variação e imprecisão conceitual são dependentes do campo disciplinar (biologia, antropologia, ciências sociais, psicologia, ecologia, geografia), das instituições e suas políticas, da escala de ação sobre o problema etc. A Política Nacional sobre Mudança do Clima (PNMC), o Ministério do Meio Ambiente (MMA) e o Intergovernmental Panel on Climate Change (IPCC) expressam conceitos que confirmam essa nossa primeira ponderação.

Partimos de algumas definições de adaptação, especialmente das definições dos relatórios ou planos governamentais. No documento Integração da adaptação às alterações climáticas na cooperação 
para o desenvolvimento (OCDE, 2011, p. 47), a adaptação consiste na redução dos "impactos das pressões do clima sobre os sistemas humanos e naturais" e deve ser pensada intrinsecamente em conjunto com as condições comportamentais, estruturais e tecnológicas. No Plano Nacional sobre Mudança do Clima - PNMC (2008, p. 87), o termo é entendido "como uma série de respostas aos impactos atuais e potenciais da mudança do clima, com objetivo de minimizar possíveis danos e aproveitar as oportunidades". Para o Painel Brasileiro de Mudanças Climáticas - PBMC (2013, p. 7), trata-se de compreender um "ajustamento nos sistemas naturais ou humanos em resposta a estímulos climáticos". Para Ebi et al., (2004, p. 36), "Adaptation is a process by which strategies to moderate, cope with and take advantage of the consequences of climate events are enhanced, developed, and implemented. [...]"'.

É preciso considerar, conforme ponderam Dupuis \& Knoepfel (2013), que a implementação nos países não tem ocorrido de forma efetiva. No Brasil, medidas e estratégias de adaptação, na forma de políticas públicas integradas (local, regional e nacional), não ganharam a devida atenção, embora seja possível verificar algumas tentativas de implementação. Em 2013, por exemplo, foi criado um Grupo de Trabalho ${ }^{2}$ com o objetivo de definir medidas para a promoção da adaptação à mudança do clima no país, assim como podemos ver as inten- ções normativas expressas na Lei n. 12.187/2009², que rege a PNMC (artigo $4^{\circ}$ ). De todo modo, alguns esforços estão sendo realizados (apesar da falta de integração), os quais acabam se fundamentando em bases conceituais mais gerais (globais).

Outro conceito essencial é o de capacidade adaptativa. De acordo com o relatório do IPCC (2007, p. 28), capacidade adaptativa é “[...] a capacidade de um sistema de se ajustar à mudança do clima (inclusive à variabilidade climática e aos eventos extremos de tempo), moderando possíveis danos, tirando vantagem das oportunidades ou lidando com as consequências". A fim de ampliar as pesquisas que envolvem diretamente as questões de dimensões sociais, o documento exemplifica algumas atividades humanas como medidas de adaptação que já vêm ocorrendo em detrimento das mudanças climáticas, como a elaboração de projetos de infraestrutura. Entre estes, podemos citar os de defesa costeira, nas Ilhas Maldivas e na Holanda, e o da Ponte da Confederação, no Canadá. No entanto, a dimensão humana, nesse caso, está condicionada a uma escala global da qual se forjam formulações de uma agenda política e, por isso, pouco se dedica à via cultural ou a particularidades locais.

Porém, há esforços que buscam a possibilidade de ação com base em outro olhar na escala da comunidade. O projeto $\mathrm{CARE}^{4}$ pode ser exemplificado neste caso: adaptação com base na comuni-

${ }^{1}$ Tradução livre: "Adaptação é um processo por meio do qual estratégias para moderar, lidar com e tirar proveito das consequências dos eventos climáticos são aprimoradas, desenvolvidas e implementadas [...]”.

${ }^{2}$ Para saber mais sobre o GT, acesse <http://www.mma.gov.br/legislacao/item/9143>. Informações sobre o Plano Nacional de Adaptação estão disponíveis em <http:/www.mma.gov.br/clima/adaptacao/plano-nacional-de-adaptacao $>$.

${ }^{3}$ Lei n. 12.187, de 29 de dezembro de 2009, que institui a Política Nacional sobre Mudança do Clima. Disponível em: <http://www.planalto.gov. br/ccivil_03/_ato2007-2010/2009/lei/112187.htm>. Acesso em: 6 out. 2017.

${ }^{4}$ CARE foi fundado em 1945. Caracteriza-se como uma organização humanitária compromissada na luta contra a pobreza global. Seu trabalho dedicase, especialmente, às condições de pobreza de meninas e mulheres pobres. Tem como objetivos, por exemplo, promover a justiça social, responder a emergências e as mudanças climáticas. O projeto CARE encontra-se ativo em diversos países. Mais informações: <http://careclimatechange. org/>. Acesso em: 23 de out. 2017. 
dade (ABC) é um dos objetivos que visam a "uma abordagem integrada, combinando o conhecimento tradicional com estratégias inovativas, para criar capacidade local de adaptação às mudanças climáticas aceleradas" (CARE, 2010, p. 2). Aumentar a resistência, levar em conta questões de gênero no âmbito da vulnerabilidade, elevar a capacidade civil local e criar estratégias de forma conjunta são algumas das diretrizes do projeto que demostram orientação mais cuidadosa no que diz respeito às potencialidades da experiência vivida. Giddens (2010, p. 208) nos apresenta outro relato dessa natureza: na Espanha, por exemplo, agricultores passaram a trabalhar juntamente com os governos municipais, com o objetivo de criarem inciativas que buscassem economizar água por meio do uso de "sistemas eletrônicos de manejo e distribuição na irrigação da lavoura".

No entanto, não é preciso ir muito longe. No Brasil, diante da crise de abastecimento vivida em São Paulo até 2015, uma série de estratégias descentralizadas começaram a aparecer como iniciativas locais ou comunitárias, visando aumentar a resiliência perante tais eventos. Aumentar o tamanho dos reservatórios residenciais, criar sistemas de coleta e armazenamento de água da chuva, entre outras iniciativas pontuais, tornaram-se atitudes frequentes, especialmente em regiões com populações com menor poder aquisitivo (Marandola Jr., 2015).

No plano ideal, todas as escalas deveriam estar inter-relacionadas em uma só teia de compromisso, a qual possibilitasse construções de redes; porém, o que se tem visto é o contrário: elas se apresentam de forma hierárquica e linear quando se trata dos problemas relativos às mudanças climáticas (Marandola Jr., 2013). Nesse sentido, abre-se um quadro de complexidade. As políticas de adaptação devem levar em consideração realidades diferentes (Giddens, 2010). É primordial, por exemplo, compreender os diversos problemas que assolam certas comunidades, como secas, chuva, pesca, energia, agricultura, biodiversidade, etc.

Como podemos pensar o crescimento histórico de secas em parte da Amazônia (Borma \& Nobre, 2013), uma vez que os rios e a floresta forneceram um modo de vida às populações ribeirinhas e às cidades na Amazônia (Oliveira, 2006)? Tendo em vista a complexidade dessa questão, Giddens (2010) afirma que essa complexidade impõe aos governos a necessidade de atender tanto aos interesses do mundo das inovações quanto aos da sociedade civil. Em outras palavras, entra em jogo a compreensão das condições geográficas, como a mudança climática em determinadas realidades, dada à especificidade dos efeitos do aquecimento global nos diferentes contextos.

Nesse cenário, podemos concordar que a insegurança social contemporânea é uma marca de nosso tempo (Marandola Jr. \& Hogan, 2006, p. 34). Há uma sobreposição de problemas ambientais e sociais: áreas de degradação ambiental passam a remeter a degradações sociais, potencializando perigos e danos (Torres, 2000). Na modernidade, observa-se o próprio declínio da razão científica, assim como o dos saberes tradicionais e religiosos. Temos, com isso, transformações nas tessituras sociais e geográficas, as quais nos levam a compreensões diferenciadas entre classes na sociedade, na distribuição, na percepção e na exposição de risco. Portanto, podemos dizer que vivemos em um período de incertezas, no qual o risco aparece como onipresente (Beck, 1992), ou seja, em todos os lugares. A vulnerabilidade, nesse contexto, emerge como a capacidade de resposta dada no qualitativo 
constituído do lugar e das pessoas, fenomenologicamente constituída, vivida e significada (Marandola Jr. \& Hogan, 2006; Marandola Jr., 2009).

Para Lindoso (2015, p. 14), quando se trata do debate da vulnerabilidade, a adaptação diz respeito à "redução de sensibilidades climáticas e aumento de capacidade adaptativa". Por seu turno, para Giddens (2010), a adaptação proativa (AP) visa diagnosticar a vulnerabilidade e dar resposta, isto é, tem importância para a compreensão dos riscos e é vista como um fenômeno econômico e social. Com efeito, a capacidade adaptativa, como fortalecedora da resiliência, cria não somente condições de maior resistência, mas, sobretudo, condições de reagir ativamente e positivamente. No meio físico, por exemplo, pode-se reforçar diques e barragens; do ponto de vista social, pode-se trabalhar com a capacidade de os grupos agirem e mudar o estilo de vida.

Logo, a adaptação é muito importante para a formulação de políticas (Giddens, 2010). Verifica-se que as capacidades de resposta e de adaptação encontram-se intrinsecamente relacionadas. Nesse caso, a adaptação apresenta-se como uma política fortalecedora (imprescindível) para as capacidades de resposta. Assim, políticas de adaptação (com o fortalecimento de políticas públicas) tornam-se fundamentais para uma intergeração das ações às respostas, o que as tornando, por excelência, uma política pública. Portanto, não temos dúvidas de que, juntamente com o estudo da vulnerabilidade, as medidas de adaptação têm papel fundamental para se pensar no nível das comunidades e potencializar todo o conhecimento ali residente.
Ao refletirmos sobre palavras como "danos" e "consequências", nos remetemos novamente a reforçar o quanto a política de adaptação, em sua visão prática, pode contribuir para a avaliação da capacidade de resposta, sobretudo das capacidades de respostas futuras: "Adaptation, whether analyzed for purposes of assessment or practice, is intimately associated with the concepts of vulnerability and adaptive capacity" " (Smit \& Wandel, 2006, p. 286). Concordamos, então, que as políticas de adaptação, como tema novo nas agendas governamentais, vêm ganhando grande espaço nas discussões no campo das ciências humanas e sociais e têm aberto nesta década novas pautas de debates relativos aos problemas ambientais.

A adaptação não é uma busca meramente por compreensões das problemáticas ou da vulnerabilidade, mas sim uma busca por planejamento e construção de políticas públicas (Marandola Jr., 2009). Isso implica reconhecer a complexidade da política de adaptação como possibilidade do fazer política e a própria compreensão da ideia de capacidade como mecanismo de fortalecimento ou de complementação das situações de vulnerabilidade (capacidade de resposta).

Esses debates, tanto os oriundos das próprias políticas quanto os advindos da construção de uma episteme (no sentido foucaultiano) do tema, revelam a permanência de uma racionalidade econômica e tecnológica e, por conseguinte, o distanciamento do mundo-da-vida (das experiências vividas). Isso fica muito forte no debate sobre as secas no Nordeste, tema historicamente complexo e que envolve o embate entre "conviver" com a seca ou "adaptar-se" a

${ }^{5}$ Tradução livre: “Adaptação, seja esta analisada para fins de avaliação ou prática, está intimamente associada com os conceitos de vulnerabilidade e capacidade de adaptação". 
esta. Conforme mostram Maciel \& Pontes (2015), a adaptação está ligada, no discurso contemporâneo sobre mudanças climáticas, à resiliência, enquanto a convivência é utilizada pelos movimentos sociais, que reclamam para si uma forte vinculação com o cotidiano, o modo de vida e a maneira própria das populações de coexistirem com a seca.

Essa discussão ganha novo âmbito no contexto das mudanças climáticas, conforme destacam Maciel \& Pontes (2015), que identificam uma tensão entre a apropriação da convivência pelos planos governamentais e pela sociedade civil organizada. Para os primeiros, os autores destacam que conviver está associado ao mitigar o efeito das secas (como no caso do texto da Lei da Convivência, em Pernambuco). No entanto, os movimentos sociais temem que a mitigação seja uma nova roupagem para o velho discurso do combate à seca e, por isso, buscam fundamentar o movimento, segundo Maciel \& Pontes (2015), em uma episteme difícil de precisar justamente porque a convivência, no caso, está ligada diretamente ao modo de vida e à maneira de habitar a região.

Quando se fala em convivência, portanto, não se fala de uma atitude fatalista nem racionalista de considerar as ações histórico-culturais de construção do modo de vida geográfico como sendo orientadas por uma leitura mítica do espaço e do ambiente. Maciel \& Pontes (2015), por exemplo, enfatizam a convivência e a adaptação como modos que coabitam o mesmo espaço geográfico do semiárido, ancorados em modos de vida distintos, mas que nem por isso não deixam de se fundamentar em uma longa trajetória que permite articular a escala local e regional de constituição de geografias com a força das escalas global e nacional, que tencionam impor um novo ordenamento no território.
Pensar as políticas de adaptação à luz do mundo-da-vida é uma possibilidade de enfatizar o sentido da coexistência e da convivência, à medida que assenta a compreensão dos riscos e perigos no cotidiano vivido. Para isso, é fundamental não hierarquizar ações oriundas dos modos de vida como desinformadas ou tecnicamente deficitárias. O componente religioso, muito presente no sertão nordestino, não é um mito a ser dissipado, mas um elemento constituinte tanto quanto a geografia física ou o processo histórico de formação territorial. É nessa direção que a preocupação com o mundo-da-vida nos ajuda a questionar: juízos apriorísticos, dicotômicos ou fragmentados.

Poderíamos, assim, construir uma ruptura (para além) dos marcos que orientam as diretrizes que condicionam os limites da política de adaptação a abordagens estritamente pragmáticas, provendo não apenas uma inversão de valores, mas acentuando a necessidade de refletir o que ainda precisa ser pensado: um conhecimento construído/constituído não somente com base na racionalidade epistêmica, mas também considerando o mundo da doxa. Nesse mundo finito, vivemos "[...] conscientes dele como horizonte dos nossos fins particulares, sejam momentâneos e mutáveis, sejam uma meta que duravelmente nos orienta" (Husserl, 2012b, p. 381). Esse mundo é constituinte de nossos valores, nos é próprio (Szilasi, 2003). Com isso, o mundo-da-vida, como um retorno à experiência, fala sobre um saber pré-lógico e pré-teórico que fundamenta a vivência comunitária entre as pessoas, assim como suas ações, suas vontades e seus desejos. Assim, vemos na seção seguinte como o retorno a esse solo significativo pode expandir os limites da adaptação. 


\section{O mundo-da-vida como abertura para o conhecimento da política de adaptação}

Para além da racionalidade (tecnológica e econômica), que outros parâmetros fundamentais podem reger as políticas de adaptação, com base na reflexão do mundo-da-vida? Diante dessa inquietação, recorremos aos enunciados de Adger $e t$ al. (2009), a fim de problematizarmos os limites que circundam a política de adaptação: segundo os autores os limites da adaptação, são, normalmente, colocados dentro das dimensões ecológicas e físicas, econômicas (custo-benefício) e tecnológicas (inovação):

$[\ldots]$ these conceptions of adaptation limits imply that such limits can be defined predominantly in either exogenous or analytical terms. The conceptions give great weight to limits imposed from 'outside society' or limits where the risk can be quantified. (Adger et al., 2009, p. 337). ${ }^{6}$

Essa reflexão reforça as ponderações de cunho pragmático já apontadas, como as visões exógenas e analíticas. Nesse sentido, os autores expressam que os limites da adaptação devem também permear quatro domínios: ética (como e o que valoramos), conhecimento (como e o que conhecemos), risco (como e o que nós percebemos) e cultura (como e a qual se vive). A inclusão desses valores é fundamental para construir outros referenciais no debate. Diante disso, de que modo o mundo-da-vida pode permear esses domínios? Neste momento, examinaremos a ética, conhecimento e cultura.

\section{1. Ética}

Nas considerações de Adger et al. (2009), os limites para a adaptação, no que tange seus objetivos finais, devem ser dependentes dos diversos valores e, com isso, residirem nas bases dos princípios éticos. Para os autores, as decisões da adaptação fundamentam-se em certos valores, tornando-os mais diversos e contraditórios, sobretudo quando se envolvem os níveis de complexidade: pequenas escalas (que dispõem de agentes individuais) e escalas maiores (que dispõem de vários agentes). Não obstante, valores na sociedade não podem ser vistos de forma isolada, pois, conforme os interesses em certos níveis de influência e poder, os valores podem se agregar ou se distanciar.

Portanto, percebemos que esses determinantes, que muitas vezes entram em confronto, devem ser pautados nas decisões da política de adaptação. Nesse sentido, a questão ética, com base nas compreensões do mundo-da-vida, pauta o compromisso com o Outro e requer, antes de tudo, o compromisso com o Eu - uma atitude e uma (auto) responsabilidade. Conforme mostra García Ruiz (2012, p. 204), no mundo-da-vida atuam os indivíduos e, uma vez sem este, haveria a impossibilidade de interações e entendimentos mútuos.

$\mathrm{Na}$ esfera da comunidade, há uma vida comunicativa sempre em permanência. Entretanto, como fica a experiência do estranho? O problema da alteridade, então, se manifesta. Não temos pretensões de aprofundar essa questão. O que nos cabe pensar eticamente é: o gestor, em sua prática cotidiana, em um cenário da problemática da experiência

\footnotetext{
${ }^{6}$ Tradução livre: "Essas concepções dos limites da adaptação implicam que tais limites podem ser definidos predominantemente em termos exógenos ou analíticos. As concepções dão maior peso aos limites impostos de 'fora da sociedade' ou aos limites em que o risco pode ser quantificado".
} 
do outro e como estranho, deve se aproximar do mundo-da-vida a fim de receber e compreender os valores construídos e atribuições no cotidiano? Com efeito, o pensamento que conduz ao entendimento da relação em termos de sujeito e objeto não pode deixar de responder a uma acusação ética. Não obstante, a ética fenomenológica, pautada especialmente na fenomenologia de Husserl, nada tem de abstrato nesse sentido; pelo contrário, conduz ao domínio de uma disciplina técnica de natureza prática ou de uma ciência da razão prática (Fabri, 2007; Trotta, 2015).

Diante do problema ético, a questão volta-se para as dimensões unitárias dos povos e todas as suas particularidades em cada tempo. Volta-se para os interesses significativos dos grupos, tanto em suas esferas particulares como universais e, portanto, tem a função "[...] de possibilitar a superação das esferas individuais, bem como dos tempos vividos particularmente" (Cavalieri, 2013, p. 423). A tecnização e objetivação da vida e da cultura pelo positivismo científico, ao produzirem o afastamento do mundo-da-vida, dirigiram "[...] a perda de valores de grande relevância no mundo moral, como a liberdade e a responsabilidade" (Cavalieri, 2010, p. 5). Para Cavalieri (2010), o mundo-da-vida, como solo universal, visa romper com o reducionismo e o cientificismo. Para ele, o cientificismo e a técnica devem estar acima das inquietações da razão e, sobretudo, ter preocupações no campo dos valores éticos e morais.
Questionamos: qual seria a importância da técnica na modernidade? 1) ela se transformou em nosso habitat; 2) instaurou a crença de que a vida pode ser toda mensurável e quantificável pelo método. Nesse sentido, o empreendimento fenomenológico (fundamentado aqui pela via do mundo-da-vida) "[...] é uma ética na medida em que se volta para as motivações fundamentais de uma cultura, não somente para esclarecê-las, mas também para questioná-las [...]" (Fabri, 2007, p. 45). Husserl (2012a), em A crise das ciências europeias e a fenomenologia transcendental, além de apontar a perda vital do mundo-da-vida, expõe toda uma tarefa de renovação (Erneurung) da cultura, apresentando um empreendimento no campo dos valores.

Este sentido trascendental de la ética permite en $\mathrm{La}$ crisis de las ciencias europeas (Hua VI) dar toda su significación y relevancia a la problemática del mundo de la vida (Lebenswelt). Es a partir de aquí cuando cobra todo su sentido la reflexión y el análisis fenomenológico de las vivencias, no tanto para establecer el contenido cognitivo de los juicios, sino para comprender el compromiso valorativo del sujeto en determinadas situaciones y la motivación que lo lleva a procesos de renovación social y cultural. La responsabilidad descubierta por la fenomenología en la pertenencia del sujeto a un contexto histórico y social se traduce en su compromiso con la renovación de la cultura que conforma dicho contexto (Vásquez, 2002, p. XII). ${ }^{7}$

\footnotetext{
${ }^{7}$ Tradução livre: "Este sentido transcendental da ética permite em a crise das ciências europeias (Hua VI) darar toda sua significação e relevância para os problemas do mundo-da-vida (Lebenswelt). É a partir daqui, que ganha todo seu sentido a reflexão e análise fenomenológica das experiências, não tanto para estabelecer o conteúdo cognitivo dos juízos, mas para compreender o compromisso valorativo do sujeito em determinadas situações e a motivação que o leva a processos de renovação social e cultural. A responsabilidade descoberta pela fenomenologia na pertença do sujeito a um contexto histórico e social se traduz em seu compromisso com a renovação da cultura que conforma o dito contexto".
} 


\subsection{Conhecimento}

O mundo-da-vida instaura a crítica do conhecimento sobre o pensamento positivo nas ciências (lógico e pautado em regras explicativas) e, sobretudo, seu afastamento da vida cotidiana (Ferreira, 2016b). Como solo da evidência originária (Husserl, 2012a), o mundo-da-vida se apresenta, como já dito, pré-científico e não teórico. Nele vivemos de forma evidente, e a partir dele todo o nosso horizonte de interesse é despertado - nele tematizamos metas e vontades. A racionalidade científica do conhecimento não tematiza a vida extracientífica. Moraes (2005, p. 88), por exemplo, demostra, por meio do relato de um pescador, as práticas e os conhecimentos tradicionais que este tem em relação à lagoa de Piató/RN: “[...] se o peixe 'ovar' dos dois lados de sua barriga, pode-se esperar um bom inverso, mas se o peixe 'ovar' apenas de um lado, esperar-se pouca chuva". Por que o mundo-da-vida é o domínio das evidencias originárias? Porque nele conservam-se os valores e as práticas de um saber acumulativo, herdado, fundado, vital para a sobrevivência de um dado grupo ou comunidade.

Este mundo de la vida no es otro que el de la simple $\delta o ́ \xi \alpha$, tradicionalmente tratada de un modo tan despectivo. En la vida extracientífica no es en absoluto desvalorizada de semejante manera; ahí significa una esfera de validaciones seguras; de aquellas que dan posibilidad y sentido a la vida total de intereses [gesamten Interessenleben] del ser humano en todos sus objetivos (Husserl, 1995, p. 17). ${ }^{8}$
O conhecimento científico (episteme) moderno é sistemático, rígido, explicativo; ele calcula, soma, resolve - retorna sempre à sua razão instrumental. $\mathrm{O}$ conhecimento do mundo-da-vida é transcendental, intuitivo e perceptivo; volta-se para a experiência (doxa), os sujeitos e as comunidades, o cotidiano e a vida circundante - é o conhecimento evidente e constituidor da subjetividade e intersubjetividade.

\subsection{Cultura}

Compreender cultura abrange os domínios anteriores: a vida ética de um determinado povo e comunidade, seu conhecimento balizado culturalmente. Fabri (2007, p. 35) expressa o pensamento fenomenológico de cultura em Husserl: “[...] a cultura é o universo espiritual em que o humano se expressa, se produz e se recria interminavelmente". É nesse sentido de recriar que a reflexão sobre o mundo-da-vida pode trabalhar. Para Adger et al. (2009), certas culturas estão sofrendo perdas irreversíveis. Isso se torna problemático, uma vez que estão depositados nelas bens culturais e, portanto, essas perdas limitam suas capacidades adaptativas. Os autores ressaltam que a cultura e os lugares não são estáticos ou limitados aos bens materiais; ao contrário, eles sempre se modificam com o tempo. Nesse sentido, Adger et al. (2009) defendem a importância de mais estudos no campo das representações e percepções culturais. Com essas considerações vejamos, com base em algumas ideias-chave (perda, limitação, renovação), como o pensamento fenomenológico pode se desenvolver.

\footnotetext{
${ }^{8}$ Tradução livre: "Este mundo-da-vida não é outro senão o da simples $\delta$ ó $\alpha$, tradicionalmente tratada de um modo depreciativo. Na vida extracientifica não é em absoluto desvalorizada de maneira semelhante; lá significa uma zona validações seguras; daquelas que dão possibilidades e significados para a vida total de interesses [gesamten Interessenleben] do ser humano em todos os seus objetivos".
} 
Iniciamos em um plano mais geral: primeiramente, entendemos o que é cultura e, posteriormente, o que são culturas.

Fabri (2007), em referência ao pensamento de Spengler, expõe que a cultura se movimenta em florescimento, desenvolvimento e esgotamento, assemelhando-se a um organismo vivo. Ressalta-se que o debate central está entorno da crise da humanidade europeia no século XX, que, para Spengler, estaria em um declínio dos valores morais. Ao apresentar o pensamento fenomenológico de Husserl, Fabri (2007) expõe a discordância: a cultura (Kultur, termo utilizado por Husserl) não se revela como uma ideia, mas sim como um universo espiritual que se recria a todo o momento. Isso significa, fenomenologicamente, que as situações culturais que possibilitaram o próprio declínio podem ser revertidas continuamente, pois elas estão fundadas na realidade física, corporal e na história (Fabri, 2007). Em outras palavras, a cultura nada teria de organismo vivo, mas estaria voltada para o mundo das pessoas.

Saindo do caráter universal de cultura, que, segundo Fabri (2007), estaria nas preocupações da ciência de essências, vejamos o caso de culturas, o qual funda-se em seu conceito universal. $\mathrm{O}$ uso do termo "culturas" implica entender as singularidades e, portanto, as particularidades. Nesse caso, entende-se que cada indivíduo se encontra voltado para seu mundo circundante (Umwelt) e, sobretudo, para ele mesmo e para os outros, aí pertencendo, formando uma teia de vida social. No mundo circundante reside os conhecimentos particulares e, dentro de suas estruturas, a constituição de uma tradição singular. Com efeito, o termo "culturas" implica compreender as verdades relativas do mundo, antes totalizado, agora para o mundo-da-vida. Vejamos uma passagem.

Cada um dos ambientes culturais possui a sua "verdade", o seu universo simbólico comum, algo de único e singular. Por outro lado, mesmo que esta verdade relativa seja portadora de um modo genuíno e autêntico de ver o mundo e de nele agir, existe um tipo de motivação cultural que aponta para um sentido universal de verdade (Fabri, 2007, p. 50).

As últimas palavras da citação exprimem que embora haja singularidades, modos de viver particulares, algumas dessas formas culturais ou várias podem se "encontrar" e passar para um estágio superior de cultura: isso ocorre quando um ideal de humanidade, em um mundo circundante particular, conduz a própria finalidade de outras culturas. Exemplificamos a filosofia dos gregos: todas as suas pretensões de ser, a busca do conhecimento científico, da razão humana, da filosofia, nos motivaram e nos motivam até hoje. Ressaltamos: somos "homens da ciência", uma cultura universal (ocidental) pautada na busca do conhecimento e de uma razão fundada na filosofia grega. Tal aceitação confirma por que a crise das ciências europeias, no que tange seu afastamento do mundo-da-vida, promove a própria crise da humanidade e do homem contemporâneo.

A reflexão sobre o mundo-da-vida, então, volta-se para os interesses humanos e para a importância dada à formação cultural de um dado grupo ou comunidade. Esta, segundo Bello (2006, p. 73), caracteriza-se "[...] pelo fato de seus membros assumirem responsabilidades recíprocas".

Se as políticas de adaptação não levarem em conta que se adaptar ou fortalecer a capacidade e a resiliência é um retorno a esse mundo, corremos o sério risco de arbitrariedades. Ao contrário, assentar 
as políticas no mundo-da-vida abre caminho para pensar outros valores vitais, porém não pelos meios, mas pelos fins últimos, ajustados em um sentido de liberdade, no plural.

Diante disso, o mundo-da-vida não pode ser entendido como um receptáculo, um espaço simbólico, um mero fenômeno de uma coisa provisória, uma representação do comportamento humano. Ele não se manifesta como aparência da coisa, um objeto que compõe a forma estética; o mundo-da-vida é a constituição fundamental da existência humana. As capacidades de adaptação, nesse cenário, são particularidades das experiências concretas e, desse modo, afirma-se a importância das intersubjetividades. Se no mundo-da-vida repousa uma razão prática ou orientada por uma razão comunicativa, por que, então, tanta demora das políticas de adaptação ao seu encontro? Por que há uma negligência de suas orientações partirem desse solo fundante?

\section{Crítica da finalidade}

Após o exame de alguns domínios levantados por Adger et al. (2009), entendemos que o mundo-da-vida permite assentar tais críticas em outro solo, o qual impõe limitações para as estratégicas das políticas, pois ainda não se pretendeu à crítica da finalidade. Assim, ir para o domínio da ética, dos valores ou da cultura requer aprofundamento não dos pressupostos lógico-teóricos, mas de uma evidência que repousa na experiência.

Jamieson (1992) concorda com essa orientação da discussão quando pondera que aquilo que se põe como problema essencial às questões climáticas não se responde unicamente pela ciência, ou por um acúmulo de seus conhecimentos sistemáticos, mas sim por um debate ético, de valores e político. $\mathrm{O}$ autor lembra que essas questões também são de interesse da própria ciência, porém, no horizonte da crítica já apresentada, a ciência moderna perdeu esse interesse em detrimento do projeto da racionalidade e por encontrar em si mesma sua própria limitação ou seja, por não tematizar a razão.

Os limites da adaptação nos planos tecnológico e econômico podem ser facilmente criticados se o retorno à experiência almejar a possibilidade do conhecimento no que tange à capacidade adaptativa e resposta de certos grupos. O discurso sobre grupos com menos capacidade de adaptação se afirma principalmente sobre os países em desenvolvimento, que sofrem especialmente com secas, enchentes, doenças, pobrezas etc. No caso do Brasil, o Nordeste e suas históricas estiagens são o grande exemplo (Maciel \& Pontes, 2015). O que parece estar em muitos argumentos sobre capacidade, nesse caso, diz respeito às condições de possibilidade "risco e custo" de um país. Vejamos nos Relatórios síntese de Mocambiquet (Aliança Africana para a Resiliência às Mudanças Climáticas - ACCRA) uma passagem sobre o pensar da capacidade de adaptação.

[...] assegurar que os indivíduos e a sociedade possam adaptar-se para além do encerramento da intervenção; Isto é crucial para os programas de adaptação, porque não há um ponto final para a adaptação: as pessoas precisam adquirir a capacidade de adaptar-se considerando várias gerações futuras; Segue o desafio para os que se envolvem com a implementação de intervenções de desenvolvimento, que é atender as necessidades imediatas e ao mesmo tempo construir a capacidade para adaptação no futuro (Arnall, 2012, p. 7). 
"Para além" ou "adquirir a capacidade de adaptação" são boas expressões para se pensar. À primeira vista, "para além" pode denotar um horizonte político mais amplo, ou seja, alicerçar outro modo de pensar a vivência concreta. A segunda expressão, entre aspas remete a uma formação, e esta inquieta: como fazer alguém adquirir capacidade? Isso significa que nem todos têm capacidade de adaptação? Estamos perdendo esse imperativo? A capacidade de adaptação não é imanente à cultura? Vamos racionalizar capacidades? Ensinar novamente? Ficamos com as interrogações. A capacidade adaptativa às mudanças climáticas não pode se sustentar somente com base em políticas pré-orientadas. Lindoso (2015) ressalta, por exemplo, que as definições científicas em torno da adaptação se tornam falhas quando passam para a agenda política sem levar em conta as dimensões necessárias do desenvolvimento sustentável.

Fomentar capacidade adaptativa deve ser uma ação horizontalizante no contexto das necessidades comunitárias do cotidiano. Possibilidades ou capacidades de adaptação não pressupõem construir ações homogêneas: comunidades ribeirinhas no Baixo Tocantins, no nordeste do Pará, expressam diferenças fundamentais daqueles que vivem nas áreas de encostas no subúrbio de Salvador. Portanto, fomentar capacidade adaptativa é construir conjuntamente potencialidades, tanto nas esferas comunitárias como no plano de ações de caráter mais geral. Não obstante, Myers (2014) traz um interessante pensamento, que busca refletir o mundo-da-vida no problema das mudanças ambientais.
Lifeworlds make experience reliable by offering a coherence and continuity to our basic intuitions. Yet they are also heterogeneous and open to the material world beyond them, which allows them to constantly develop and change over time. As collective sensibilities develop in response to concrete problems, moreover, they both cohere and conflict with other ways of making sense of things at various levels of generality and specificity (Myers, 2014, p. 60). ${ }^{9}$

Desse modo, o autor reforça (o que já se ponderou) que o mundo-da-vida não pode ser visto como algo abstrato, mas sim como o mundo da experiência concreta das pessoas. Myers (2014) ressalta ainda que ele descortina as formas culturais, os valores, ou seja, os pressupostos que buscam tornar as informações homogêneas. O mundo-da-vida apresenta a heterogeneidade desde uma dimensão específica da vida até questões mais gerais. Portanto, pensar em capacidade ou políticas adaptativas no chão de sua heterogeneidade mobiliza, de maneira contundente, o mundo-da-vida para a ampliação de outros domínios.

É necessário frisar a reflexão do mundo-da-vida na política de adaptação: a capacidade adaptativa está na ordem das particularidades, isto é, fomentar, possibilitar e adquirir capacidade adaptativa não pode ser algo pré-dado (lógico), mas sim algo construído conforme os modos de vida de cada comunidade, de cada grupo etc. Adaptar-se às mudanças climáticas requer buscar na experiência vivida, na vida intersubjetiva, o conhecimento necessário para fortalecer ou criar condições de possibilidade de adaptação a curto e a longo prazo.

\footnotetext{
${ }^{9}$ Tradução livre: “O mundo-da-vida torna as experiências confiáveis ao oferecer uma coerência e continuidade às nossas intuições básicas. Contudo, ele também é heterogêneo e aberto ao mundo material para além dele, o que lhe permite constante desenvolvimento e mudança ao longo do tempo. À medida que sensibilidades coletivas se desenvolvem em resposta a problemas concretos, se aderem e se opõem a outras formas de fazer sentido das coisas em vários níveis de generalidade e especificidade".
} 
O mundo-da-vida vem, então, para pensar situações significativas, porém não como escala, mas como experiências em uma universalidade.

\section{Fenomenologias do mundo-da-vida}

As dimensões que o mundo-da-vida impõe para pensar as políticas de adaptação não são, em si, novidades. Os estudos de ecologia humana ou da própria geografia também têm lidado com a questão sobre a adaptação das populações às mudanças ambientais (Berdoulay\& Soubeyran, 2014).

De um lado, outras perspectivas epistemológicas já têm, de diferentes formas, reclamado a necessidade de participação dos sujeitos na formulação de políticas (Rebotier, 2011) ou da necessidade de inserção destes nos processos de participação e tomada de decisão (Ribeiro, 2008). De outro, junto com a ideia de adaptação, outras perspectivas procuram tensionar seu sentido, reclamando de diferentes formas uma perspectiva crítica e mais integrada, tanto da compreensão dos fenômenos quanto de suas repercussões para o planejamento e a formulação das políticas: aceitabilidade (Rebotier et al., 2015), convivência (Maciel \& Pontes, 2015), imunidade (Garcia, 2015), resiliência (Marandola Jr., 2014).

No entanto, como mostram Di Giulio et al. (2016),

Ainda que tais perspectivas tenham sua relevância, elas falham em dois principais aspectos: (i) são insuficientes na compreensão de como os determinantes influenciam e interagem sinergicamente uns com os outros na elaboração das respostas às mudanças climáticas e na capacidade de adaptação; (ii) apresentam inconsistências para a análise de casos empíricos.
É nesse horizonte que a reflexão sobre mundo-da-vida busca enriquecer o tema, uma vez que ele é o solo significativo da experiência, do qual as pessoas constroem sentidos de mundo e de vivência. Nele se produz um conhecimento direto, visto que é cumulativo das formas culturais e de identidades e, com base nisso, cria condições autoevidentes com base na própria experiência acumulada, gerando novos conhecimentos. Assim, o mundo-da-vida é o próprio mundo construído pelas sociedades, histórico e da existência concreta (Morujão, 1988).

Assentado em uma perspectiva empírica que é, ao mesmo tempo, transcendental, o mundo-da-vida constituiu-se como contribuição para a formulação de pesquisas que partam da experiência em realidades e escalas específicas, fornecendo uma via de articulação transescalar. Considerando seu caráter na existência concreta, ponderamos que as relações sociais são constituídas por uma normatividade (de valores, princípios, linguagem, comunicação) fundamentada por um agir orientado pelo entendimento socialmente construído. Queremos fortalecer a compreensão de que as relações sociais são guiadas por intencionalidades e valores, ou seja, para além da normatividade das instituições e do sistema (Estado, trabalho, Igreja, dinheiro, mídia etc.), há uma que subjaz no mundo-da-vida e que fundamenta toda a nossa vida intramundana. Trata-se, portanto, de uma fenomenologia da vida cotidiana que permite lançar outra luz ao debate sobre as políticas públicas, contribuindo decisivamente para a construção de uma epistemologia da diversidade em uma chave ética renovada, ou seja, cujo sentido político do conhecimento fundamente uma reorientação do próprio processo de conceber e de fazer política.

Os exemplos estão aí e mostram, de um lado, o fracasso de políticas impostas, de cima para baixo, 
que muitas vezes não alcançam nem mesmo êxito econômico, e, de outro, ações simples operadas no mundo-da-vida que nem chegam a constituírem políticas, mas que produzem efeitos em termos de capacidade adaptativa e de respostas surpreendentes. Uma epistemologia da diversidade não deve hierarquizar tais soluções, mas sim trazer para si a tarefa de encontrar formas de articulação de tais saberes e ações, orientados por outros marcos de pensar e de se fazer política.

\section{Referências}

Adger, W. N.; Dessai, S; Goulden, M.; Hulme, M.; Lorenzoni, I.; Nelson, D. R.; Naess, L. O.; Wolf, J.; Wreford, A. Are There Social Limits to Adaptation to Climate Change? Climatic Change, 93, 335-354, 2009. doi: 10.1007/s10584008-9520-z

Arnall, A. H. Compreendendo a capacidade adaptativa ao nivel local em Moçambique. Aliança Africana para a Resiliência às Mudanças Climáticas (ACCRA). Relatório síntese de Mocambiquet, 2012. Disponível em: <http:// www.cebem.org/cmsfiles/publicaciones/Comprendiendo_capacidade_moz.pdf $>$. Acesso em: mar. 2017.

Beck, U. Risk Society. London: Polity, 1992.

Borma, L. S; Nobre, C. A. (Orgs.). Secas na Amazônia: causas e consequências. Editora: Oficina de Textos, 2013.

Bello, A. Introdução à Fenomenologia. Tradução de Jacina Turolo Garcia e Miguel Mahfoud. Bauru, São Paulo: Edusc, 2006.

Berdoulay, V.; Soubeyran, O. Adaptation, Science de la durabilité et pensé planificatrice, Natures Sciences Sociètés, 22, 114-123, 2014. doi: 10.1051/nss/2014024

CARE. O que é adaptação às mudanças climáticas? Outubro de 2010. Disponível em: $<$ http://www.careclimatechange.org/files/adaptation/O_que_e_\%20a_adaptacao_a_mudanca_climatica.pdf $>$. Acesso em: mar. 2017.

Cavalcanti, C. Política de governo para o desenvolvimento sustentável: uma introdução ao tema e a esta obra coletiva. In: Cavalcanti, C. (Org.). Meio ambiente, desenvolvimento sustentável e politicas públicas. São Paulo: Cortez, 1997. p. 21-40.

Cavalieri, E. O rigor científico como questão ética em Edmund Husserl. In: Anais do IV Seminário Internacional de Pesquisa e Estudos Qualitativos. São Paulo: UNESP-Rio Claro - IB, 2010.

Cavalieri, E. A via a-teia para Deus e a constituição de uma ética teleológica a partir do pensamento de Edmund Husserl. Vitória: EDUFES, 2013.

Di Giulio, G. M.; Martins, A. M. B. B.; Lemos, M. C. Adaptação climática: fronteiras do conhecimento para pensar o contexto brasileiro. Estudos Avançados, 30, 25-41, 2016. doi: 10.1590/S0103-40142016.30880004

Dupuis, J.; Knoepfel, P. The adaptation policy paradox: the implementation deficit of policies framed as climate change adaptation. Ecology and Society, 18(4): 31, 2013. doi: 10.5751/ES-05965-180431

Ebi, K. L; Lim, B; Aguilar, Y. Scoping and designing an adaptation project. In: Lim, B; Spanger-Siegfried, E. (Orgs.). Adaptation Policy Frameworks for Climate Change: developing strategies, policies and measures. Cambridge University Press, Cambridge, 2004. p. 35-46.

Fabri, M. Fenomenologia e cultura: Husserl, Levinas e a motivação ética do pensar. Porto Alegre: EDIPUCRS, 2007.

Ferreira, R. B. As estruturas do mundo-da-vida e seu significado para a Geografia. In: Anais do XI Encontro Nacional da ANPEGE. Presidente Prudente/SP, 9 a 12 de out., 2015.

Ferreira, R. B. Mundo-da-vida como fundamento vital para as políticas de adaptação. Dissertação (Mestrado Interdisciplinar em Ciências Humanas e Sociais Aplicadas) - FCA/ UNICAMP, 2016a.

Ferreira, R. B. Husserl, mundo-da-vida e geografia. Revista da Abordagem Gestáltica, 22(2), 119-126, 2016b. Disponível em: http://pepsic.bvsalud.org/scielo.php?script=sci_abstract\&pid=S1809-68672016000200002

Floriani, D. Crítica da razão ambiental: pensamento e ação para a sustentabilidade. São Paulo: Annablume, 2013. 
Garcia, P. O. Adaptativité ou immunité aux changements anthropocéniques? Les rationalités de l'adaptation oau changement climatique. In: Berdoulay, V.; Soubeyran, O. (Orgs). Aménager pour s'adapter au changement climatique: un rapport à la nature à reconstruire? 1ed. Pau: Presses de l'Université de Pau et des Pays de l'Adour, 2015. p. 113-130.

García Ruiz, P. E. El problema de la experiencia del otro y el sentido de una ética fenomenológica. Acta Fenomenológica Latinoamericana, 6, 197-221, 2012. Disponível em: http:// www.clafen.org/AFL/V4/197-221_ST2-P_GarciaR.pdf

Giddens, A. A política da mudança climática. Tradução Vera Ribeiro. Rio de Janeiro: Zahar, 2010.

Husserl. E. Tres anexos de La crises sobre el mundo de la vida, Investigaciones fenomenológicas. 1, 7-20, 1995. Disponível em: http://www2.uned.es/dpto_fim/InvFen/ InvFen01/pdf/01_HUSSERL.pdf

Husserl. E. A crise das ciências europeias e a fenomenologia transcendental: uma introdução à filosofia fenomenológica. Tradução de Diogo Falcão Ferrer. Rio de Janeiro: Forense Universitária, 2012a.

Husserl. E. Anexos XVII, XVIII, XIX e XX. In: . A crise das ciências europeias e a fenomenologia transcendental: uma introdução à filosofia fenomenológica. Tradução de Diogo Falcão Ferrer. Rio de Janeiro: Forense Universitária, 2012b. p. $380-388$.

IPCC - Intergovernmental Panel on Climate Change. $\mathrm{Mu}$ dança climática 2007: mitigação e mudanças climáticas, sumário para os formuladores de políticas. Disponível em: <http://www.ipcc.ch/pdf/reportsnonUN-translations/ portuguese/ar4-wg1-spm.pdf $>$. Acesso em: 20 de jun. 2015.

Jamieson, D. Ethics, Public Policy, and Global Warming, Science, Technology, \& Human Values, 17(2), 139-153, 1992. doi: 10.1177/016224399201700201

Korelc, M. Teleologia e vontade segundo Husserl. Educação e Filosofia. 27(53), 343-382, 2013. Disponível em: http:// www.seer.ufu.br/index.php/EducacaoFilosofia/article/ view/13738

Leff, E. Epistemologia ambiental. São Paulo: Cortez, 2001.

Lindoso, D. P. Adaptação à mudança climática: ciência, política e desenvolvimento sustentável. ClimaCom Cultura
Científica, 02, 1-21, 2015. Disponível em: http://climacom. mudancasclimaticas.net.br/?p=1967

Maciel, C.; Pontes, E. T. Seca e convivência com o semiárido: adaptação ao meio e patrimonialização da Caatinga no Nordeste brasileiro. Niterói: Consequência, 2015.

Marandola Jr, E. Tangenciando a vulnerabilidade. In: Hogan, D. J.; Marandola Jr., E. (Orgs.). População e mudança climática: dimensões humanas das mudanças climáticas. - Campinas: Núcleo de Altos Estudos-Nepo. Unicamp. Brasília: UNFPA, 2009. p. 29-52.

Marandola Jr, E. As escalas da vulnerabilidade e as cidades: interações trans e multiescalares entre variabilidade e mudança climática. In: Ojima, R; Marandola Jr., E. (Orgs). Mudanças climáticas e as cidades: novos e antigos debates na busca da sustentabilidade urbana e social. São Paulo: Blucher, 2013. p. 91-114.

Marandola Jr, E. A escolha de Sofia? ou o dilema da segurança humana nos desastres: qual agenda brasileira? In: Valencio, N.; Siena, M. (Orgs.). Sociologia dos Desastres: construção, interfaces e perspectivas. São Carlos: RiMA, 2014. p. 91-108.

Marandola Jr, E. Vulnerabilité, adaptation et résilience: une approache expérientielle. In: Berdoulay, V.; Soubeyran, O. (Orgs.). Aménager pour s'adapter au changement climatique: un rapport à la nature à reconstruire? Pau: Presses de l'Université de Pau et des Pays de l'Adour, 2015. p. 95-107.

Marandola Jr., E; Hogan, D. J. As dimensões da vulnerabilidade. São Paulo em Perspectiva, 20(1), 33-43, 2006. Disponível em: http://produtos.seade.gov.br/produtos/spp/ index.php?men=res

Moraes, S. C. Saberes da Pesca: uma arqueologia da ciência da tradição. Tese (Doutorado) - UFRN, 2005.

Morujão, A. F. Estrutura e sentido do "Mundo da Vida". Revista portuguesa de Filosofia. 44 (3), 367-381, 1988. Disponível em: http://www.publicacoesfacfil.pt/product. php?id_product $=374$

Myers, T. C. Understanding climate change as an existential threat: confronting climate denial as a challenge to climate ethics. De Ethica. A Journal of Philosophical, Theological and Applied Ethics, 1(1), 53-70, 2014. Disponível em: 
http://www.de-ethica.com/archive/contents/default.asp?doi=10.3384/de-ethica.2001-8819.14v1i1

Noguera, A. P. El reencantamiento del mundo. Mexico: PNUMA, 2004.

OCDE - Organização para a Cooperação e Desenvolvimento Econômico. Integração da Adaptação às Alterações Climáticas na Cooperação para o Desenvolvimento: guia para o desenvolvimento de políticas, OECD Publishing, 2011. Disponível em: $<$ http://www.oecdbookshop.org/get-it. php?REF=5KGHSG2GVNS4\&TYPE=browse $>$. Acesso em: abr. de 2017

Oliveira, J. A. A cultura, as cidades e os rios na Amazônia. Ciência e Cultura, 58(3), 27-29, 2006. Disponível em: http://cienciaecultura.bvs.br/scielo.php?script=sci_arttext\&pid=S0009-67252006000300013

PBMC - Painel Brasileiro de Mudanças Climáticas. Impactos, Vulnerabilidades e Adaptação. Brasília, 2013. Disponível em: < http://www.pbmc.coppe.ufrj.br/documentos/ MCTI_PBMC_sumario_executivo_impactos_vulnerabilidades_e_adaptacao_WEB_3.pdf $>$.Acesso em: out. de 2016

PNMC - Plano Nacional sobre Mudança do Clima. Brasília, 2008. Disponível em: $<$ http://www.mma.gov.br/estruturas/ smcq_climaticas/_arquivos/plano_nacional_mudanca_clima.pdf $>$. Acesso em: mar. de $201 \overline{7}$.

Rebotier, J.; Fortin, M. J.; Salvestroni, P. Entre urgence d'adaptation et recherche d'acceptabilité. In: Berdoulay, V.; Soubeyran, O. (Orgs.). Aménager pour s'adapter au changement climatique: un rapport à la nature à reconstruire? 1ed. Pau: Presses de l'Université de Pau et des Pays de l'Adour, 2015. p. 199-212.
Rebotier, J. Habiter les territoires et construir eles risques: entre empreintes spatiales et logiques sociales. In: November, V.; Penelas, M.; Viot, P. (Orgs.). Habiter les terroires à risques. Lausanne: Presses Polytechniques et Universitaires Romandes, 2011. p. 81-100.

Ribeiro, W. C. Impactos das mudanças climáticas em cidades no Brasil. Parcerias Estratégicas, 27, 297-321, 2008. Disponível em: http://laboratorios.cetesb.sp.gov.br/ wp-content/uploads/sites/28/2014/05/ribeiro_impactos.pdf

Smit, B.; Wandel, J. Adaptation, adaptive capacity and vulnerability. Global Environmental Change, 16(3), 282-292, 2006. doi: 10.1016/j.gloenvcha.2006.03.008

Szilasi, W. Introducción a la fenomenología de Husserl. Buenos Aires: Amorrortu editores, 2003.

Torres, H. Demografia do risco ambiental. In: Torres, H.; Costa, H. (Orgs.). População e meio ambiente: debates e desafios. São Paulo: Senac, 2000. p. 53-73.

Trotta, W. Reflexão acerca dos elementos constitutivos da ética husserliana. Cadernos da EMARF, Fenomenologia e Direito, 7(2), 1-124, 2015. Disponível em: http://emarf.trf2. jus.br/site/revistavolumes.php

Vásquez, G. H. La ética fenomenológica como responsabilidad para la renovación cultural. In: HUSSERL, E. Renovación del hombre y de la cultura. Barcelona: Anthropos, 2002, p. VII- XXXIII. 